\title{
Analisis Kelayakan Pengembangan Usaha Pasta Kangen Jupiter dan Mogot Jakarta Barat dengan Menggunakan Metode Capital Budgeting Tahun 2019-2023 (Feasibility Analysis of Pasta Kangen Jupiter and Mogot West Jakarta Business Development Using Capital Budgeting Method 2019-2023)
}

Ni Puthu Eka Wardani Haliasih ${ }^{1 *}$, Pambuko Naryoto ${ }^{2}$

Fakultas Ekonomi dan Bisnis, Universitas Budi Luhur, Jakarta Selatan ${ }^{1,2}$ niputhueka60@gmail.com $^{{ }^{*}}$, pambuko.naryoto@ budiluhur.ac.id ${ }^{2}$

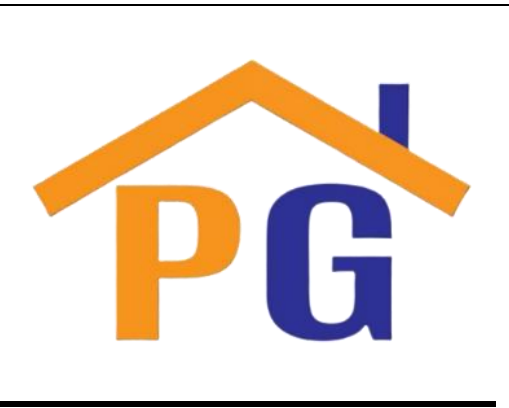

Riwayat Artikel

Diterima pada 20 Oktober 2020

Direvisi pada 1 April 2021

Disetujui pada 18 Juni 2021

\begin{abstract}
Purpose: This study aimed to determine the feasibility of establishing the Pasta Kangen Jupiter dan Mogot Jakarta Barat in West Jakarta.

Research methodology: The assessment is reviewed with Capital Budgeting in Optimistic, Moderate, and Pessimistic versions. Several methods include Payback Period, Net Present Value, Profitability Index, Average Rate of Return, Internal Rate of Return, dan Discounted Payback Period.

Results: Based on the results of calculations using the Optimistic and Moderate Version of Capital Budgeting method, Pasta Kangen Jupiter Daan Mogot Jakarta Barat business in West Jakarta is feasible to run, while the Pessimistic Version is not feasible to run.

Keywords: Capital Budgeting, Payback Period, Net present Value, Profitability Index, Average Rate of Return, Internal Rate of Return, Discounted Payback Period.

How to cite: Haliasih, N. P. E. W., \& Naryoto, P. (2021). Analisis Kelayakan Pengembangan Usaha Pasta Kangen Jupiter dan Mogot Jakarta Barat dengan Menggunakan Metode Capital Budgeting Tahun 2019-2023. Reviu Akuntansi, Manajemen, dan Bisnis, 1(1), 9-14.
\end{abstract}

\section{Pendahuluan}

Sampai saat ini usaha dibidang kuliner masih sangat menjanjikan. Karena masalah makanan yang sehat merupakan kebutuhan primer dari setiap orang. Setiap usaha perlu dilakukan studi kelayakan bisnis agar diketahui apakah usaha tersebut layak untuk dijalakan atau tidak. Di dalam studi kelayakan bisnis akan dibahas mengenai kelayakan dalam beberapa aspek penting yaitu aspek pemasaran, aspek teknik dan teknologi, aspek manajemen, aspek hukum, aspek finansial.

\section{Tinjauan Pustaka}

Pengertian studi kelayakan bisnis

Studi Kelayakan Bisnis merupakan mempelajari secara mendalam tentang suatu kegiatan agar perusahaan yang akan berdiri berjalan sesuai harapan baik dalam jangka pendek maupun jangka panjang serta mengukur seberapa besar usaha tersebut baik dalam situasi mendukung maupun tidak mendukung.

\section{Investasi}

Menurut Sinaga (2009:13-14), Investasi merupakan penggunaan sejumlah sumber-sumber produksi atau sumber-sumber daya yang ditanamkan dalam suatu proyek yang direncanakan untuk dilaksakan, dengan tujuan akan diperoleh suatu manfaat baik langsung yang berhubungan dengan barang atau jasa yang akan dihasilkan oleh proyek. 


\section{Capital Budgeting}

Hery (2015) Capital Budgeting adalah Proses perencanaan pengeluaran uang, dimana hasil pengembaliannya diharapkan terjadi dalam jangka waktu satu tahun.

\section{Payback Period (PP)}

Metode Payback Period (PP) adalah jangka waktu kembalinya investasi yang telas dikeluarkan melalui keuntungan yang didapatkan dari suatu proyek yang sudah dijalankan dengan rumus perhitungan sebagai berikut:

$$
P P=\frac{\text { Investasi Bersih }}{\text { Kas Bersih/Tahun }} X 12 \text { Bulan }
$$

Sumber : Kasmir dan Jakfar (2014)

\section{Net Present Value (NPV)}

Net Present Value adalah selisih antara pengeluaran dan pemasukan yang telah didskontokan dengan menggunakan social opportunity cost of capital sebagai diskon faktor atau dengan kata lain merupakan arus kas yang diperkirakan pada masa yang akan datang. Rumus yang bisa digunakan dalam menghitung NPV adalah sebagai berikut :

$$
\mathrm{NPV}=\frac{\text { kas bersih } 1}{(1+\mathrm{r})^{1}}+\frac{\text { kas bersih } 2}{(1+\mathrm{r})^{2}}+\cdots \frac{\text { kas bersih } \mathrm{n}}{(1+\mathrm{r})^{\mathrm{n}}}
$$

Sumber: Kasmir dan Jakfar (2012:103)

\section{Profitability Index (PI)}

Menurut Ahmad Rodani dan Herni Ali (2014) Profitability Index dapat dihitung sebagai berikut:

$$
P I=\frac{\text { Total PV of Future Cash Flow }}{\text { Intitial Investment }}
$$

Sumber: Ahmad Radoni dan Herni Ali (2014:62)

\section{Average Rate of Return (ARR)}

Average Rate of Return (ARR) digunakan untuk menilai profitabilitas investasi berdasarkan informasi yang terdapat dalam laporan keuangan tahunan. Adapun rumusnya sebagai berikut:

$$
\mathrm{ARR}=\frac{\text { Rata }- \text { rata EAt }}{\text { rata }- \text { rata Investasi }} \times 100 \%
$$

Sumber: Danang Sunyoto (2015:103)

\section{Internal Rate of Return (IRR)}

Internal Rate of Return adalah metode untuk menghitung tingkat Bungan yang dapat menyamakan antara present value dari smeua aliran kas masuk dengan aliran kas keluar dari suatu proyek.

$$
I R R=P 1-C 1 X \frac{P 2-p 1}{C 2-C 1}
$$




\section{Discounted Payback Period (DPP)}

Menyadari akan metode payback period, beberapa pembuat keputusan mempunyai varian yang disebut dengan Discounted payback period. Dengan rumus sebagai berikut:

$$
D P P=\frac{\text { Investasi }}{\text { Arus Kas yang sudah didiskontokan / Tahun }} X 12 \text { bulan }
$$

Sumber: Kamaliuddin dan Rini Indriani (2012)

\section{Metode Penelitian}

Data terkumpul dievaluasi dan diklarifikasikan sesuai dengan topic pembahasan skripsi. Alat analisis yang dipergunakan dalam penelitian adalah capital budgeting yang terdiri dari beberapa metode penelitian investasi meliputi:
a. Payback Period (PP)
b. Net Present Value (NPV)
c. Profitability Index (PI)
d. Internal Rate of Return (IRR)
e. Average Rate of Return (ARR)
f. Discounted Payback Periode (DPP)

\section{Hasil dan pembahasan} Perhitungan Total Investasi

Tabel 1. Total Investasi Versi Optimis Pengembangan Usaha Pasta Kangen Jupiter Daan Mogot

\begin{tabular}{|c|c|}
\hline Perkiraan Biaya & Total (IDR) \\
\hline Total Aktiva Tetap & 23.114 .000 \\
\hline Total Modal Kerja & 1.979 .044 .000 \\
\hline Total Investasi & $\mathbf{2 . 0 0 2 . 1 5 8 . 0 0 0}$ \\
\hline
\end{tabular}

Sumber : Data diolah

Berdasarkan 1 diketahui bahwa besarnya total perkiraan investasi kelayakan pengembangan usaha Pasta Kangen Jupiter tahun 2019-2023 sebesar Rp 2.002.158.000

\section{Perkiraan Modal dari Pinjaman}

Tabel 2. Modal Pinjaman Versi Optimis Pengembangan Usaha Pasta Kangen Jupiter Daan Mogot

\begin{tabular}{|l|c|}
\hline \multicolumn{1}{|c|}{ Keterangan } & Total \\
\hline Modal Pinjaman & 2.002 .158 .000 \\
\hline Bunga 9\% Bank BNI & 180.194 .220 \\
\hline
\end{tabular}

Sumber: Pemilik Pasta Kangen Jupiter 
Bedasarkan tabel 2, diperoleh bunga pinjaman sebesar Rp 180.194.220 yang diperoleh melalui pinjaman Bank. Jumlah bunga tersebut akan dimasukkan kedalam perkiraan tabel Arus Kas Versi Optimis.

\section{Perkiraan Arus Kas Versi Optimis}

Setelah mengetahui pendapatan dari biaya, maka selanjutnya membuat perkiraan arus kas, yaitu sebagai berikut:

Tabel 3. Perkiraan Arus Kas Versi Optimis Pengembangan Usaha Pasta Kangen Jupiter Tahun 20192023

\begin{tabular}{|l|r|r|r|r|r|}
\hline \multirow{2}{*}{ Keterangan } & \multicolumn{6}{|c|}{ Asumsi Rata-Rata Pertahun } \\
\cline { 2 - 6 } & \multicolumn{1}{|c|}{$\mathbf{2 0 1 9}$} & \multicolumn{1}{|c|}{$\mathbf{2 0 2 0}$} & \multicolumn{1}{|c|}{$\mathbf{2 0 2 1}$} & \multicolumn{1}{|c|}{} & \multicolumn{1}{|c|}{$\mathbf{2 0 2 3}$} \\
\hline Pendapatan & $\mathbf{2 . 2 0 4 . 7 4 8 . 0 0 0}$ & $\mathbf{2 . 4 2 5 . 2 2 2 . 8 0 0}$ & $\mathbf{2 . 6 6 7 . 7 4 5 . 0 8 0}$ & $\mathbf{2 . 9 3 4 . 5 1 9 . 5 8 8}$ & $\mathbf{3 . 2 2 7 . 9 7 1 . 5 4 7}$ \\
\hline (Total Biaya) & 1.979 .044 .000 & 2.038 .415 .320 & 2.099 .567 .780 & 2.162 .554 .813 & 2.227 .431 .457 \\
\hline (Depresiasi) & 5.847 .194 & 5.847 .194 & 5.847 .194 & 5.847 .194 & 5.847 .194 \\
\hline EBIT & $\mathbf{2 1 9 . 8 5 6 . 8 0 6}$ & $\mathbf{3 8 0 . 9 6 0 . 2 8 6}$ & $\mathbf{5 6 2 . 3 3 0 . 1 0 6}$ & $\mathbf{7 6 6 . 1 1 7 . 5 8 1}$ & $\mathbf{9 9 4 . 6 9 2 . 8 9 5}$ \\
\hline (Bunga 9\%) & 180.194 .220 & 180.194 .220 & 180.194 .220 & 180.194 .220 & 180.194 .220 \\
\hline EBT & $\mathbf{3 9 . 6 6 2 . 5 8 6}$ & $\mathbf{2 0 0 . 7 6 6 . 0 6 6}$ & $\mathbf{3 8 2 . 1 3 5 . 8 8 6}$ & $\mathbf{5 8 5 . 9 2 3 . 3 6 1}$ & $\mathbf{8 1 4 . 4 9 8 . 6 7 5}$ \\
\hline $\begin{array}{l}\text { (Tax 5\%- } \\
\text { 15\%) }\end{array}$ & 1.983 .129 & 30.114 .910 & 57.320 .383 & 87.888 .504 & 122.174 .801 \\
\hline EAT & $\mathbf{3 7 . 6 7 9 . 4 5 6}$ & $\mathbf{1 7 0 . 6 5 1 . 1 5 6}$ & $\mathbf{3 2 4 . 8 1 5 . 5 0 3}$ & $\mathbf{4 9 8 . 0 3 4 . 8 5 6}$ & $\mathbf{6 9 2 . 3 2 3 . 8 7 4}$ \\
\hline $\begin{array}{l}\text { D + I }(1- \\
\text { Tax) }\end{array}$ & 177.031 .703 & 159.012 .281 & 159.012 .281 & 159.012 .281 & 159.012 .281 \\
\hline Proceeds & $\mathbf{2 1 4 . 7 1 1 . 1 6 0}$ & $\mathbf{3 2 9 . 6 6 3 . 4 3 7}$ & $\mathbf{4 8 3 . 8 2 7 . 7 8 5}$ & $\mathbf{6 5 7 . 0 4 7 . 1 3 8}$ & $\mathbf{2 . 8 3 3 . 8 8 9 . 3 2 2}$ \\
\hline DF 9\% & 0,917 & 0,842 & 0,772 & 0,708 & 0,650 \\
\hline $\begin{array}{l}\text { PV of } \\
\text { Proceeds }\end{array}$ & $\mathbf{1 9 6 . 8 9 0 . 1 3 3}$ & $\mathbf{2 7 7 . 5 7 6 . 6 1 4}$ & $\mathbf{3 7 3 . 5 1 5 . 0 5 0}$ & $\mathbf{4 6 5 . 1 8 9 . 3 7 4}$ & $\mathbf{1 . 8 4 2 . 0 2 8 . 0 5 9}$ \\
\hline
\end{tabular}

Sumber: Data yang di olah

Pendapatan dalam arus kas pada tabel 3 adalah perkiraan pendapatan optimis usaha Pasta Kangen Jupiter selama 5 tahun yaitu pada tahun 2019-2023 yang setiap tahunnya naik rata-rata $10 \%$ sementara untuk perkiraan total biaya naik $3 \%$ yang didasarkan pada tingkat inflasi.

\section{Simpulan Hasil Analisis Metode Versi Optimis}

Berdasarkan hasil perhitungan dengan menggunakan metode analisis Capital Budgeting. Maka hasilnya dapat disimpulkan pada tabel 4 sebagai berikut:

Tabel 4. Hasil Perkiraan Capital Budgeting Versi Optimis Pengembangan Usaha Jupiter Tahun 20192023

\begin{tabular}{|c|c|c|c|}
\hline Metode & Hasil Analisis & Standar Unit Usaha & Keterangan \\
\hline PP & 4 Tahun 2 Bulan & PP Max 5 Tahun & Layak \\
\hline NPV & 1.153 .041 .230 & NPV $>0$ & Layak \\
\hline PI & $1,5 \mathrm{kali}$ & PI $>1$ & Layak \\
\hline ARR & $34 \%$ & ARR Min 9\% & Layak \\
\hline IRR & $27 \%$ & DF $>9 \%$ & Layak \\
\hline DPP & 4 Tahun 2 bulan & DPP Max 5 Tahun & Layak \\
\hline
\end{tabular}

2021 | Reviu Akuntansi, Manajemen, dan Bisnis/Vol 1 No 1, 9-14 
Sumber: Data diolah

Simpulan Hasil Analisis Metode Versi Moderat

Berdasarkn hasil perhitungan dengan menggunakan metode analisis Capital Budgeting. Maka hasilnya dapat disimpulkan pada tabel 5 sebagai berikut:

Tabel 5. Hasil Perkiraan Capital Budgeting Versi Moderat Pengembangan Usaha Pasta Kangen Jupiter

\begin{tabular}{|c|c|c|c|}
\hline Metode & Hasil Analisis & Standar Unit Usaha & Keterangan \\
\hline PP & 4 Tahun 6 Bulan & PP Max 5 Tahun & Layak \\
\hline NPV & 340.300 .879 & NPV > 0 & Layak \\
\hline PI & $1,2 \mathrm{kali}$ & PI $>1$ & Layak \\
\hline ARR & $16 \%$ & ARR Min 9\% & Layak \\
\hline IRR & $14 \%$ & DF $>9 \%$ & Layak \\
\hline DPP & 4 Tahun 8 Bulan & DPP Max 5 Tahun & Layak \\
\hline
\end{tabular}

Sumber: Data diolah

\section{Simpulan Hasil Analisis Metode Versi Pesimis}

Berdasarkan hasil perhitungan dengan menggunakan metode analisis Capital Budgeting. Maka hasilnya dapat disimpulkan sebagai berikut:

Tabel 6. Hasil Perkiraan Capital Budgeting Versi Pesimis Pengembangan Usaha Pasta Kangen Jupiter

\begin{tabular}{|c|c|c|c|}
\hline Metode & Hasil Analisis & Standar Unit Usaha & Keterangan \\
\hline PP & 4 Tahun 8 Bulan & PP Max 5 Tahun & Layak \\
\hline NPV & -57.276 .468 & NPV $>0$ & Tidak Layak \\
\hline PI & 0,9 kali & PI $>1$ & Tidak Layak \\
\hline ARR & $1 \%$ & ARR Min 9\% & Tidak Layak \\
\hline IRR & $8 \%$ & DF $>9 \%$ & Tidak Layak \\
\hline DPP & 5 Tahun 7 Bulan & DPP Max 5 Tahun & Tidak Layak \\
\hline
\end{tabular}

Sumber : Data diolah

\section{Kesimpulan}

Berdasarkan hasil analisis sebelumnya maka dapat disimpulkan bahwa pendirian Pasta Kangen Jupiter Daan Mogot Jakarta Barat tahun 2019-2023 dengan menggunakan metode Capital Budgeting, sebagai berikut:

1. Besarnya investasi untuk penelitian Pasta Kangen Jupiter Daan Mogot Jakarta Barat tahun 20192023 versi optimis, moderat, dan pesimis adalah sebagai berikut:

- Investasi versi optimis sebesar Rp. 2.002.158.000

- Investasi versi moderat sebesar Rp. 1.597.734.000

- Investasi versi pesimis sebesar Rp. 1.232.580.400

Berdasarkan analisis dengan metode Capital Budgeting:

a. Dengan pendekatan optimis, usaha Pasta Kangen Jupiter Daan Mogot Jakarta Barat dinyatakan layak untuk dijalankan. 
b. Dengan pendekatan moderat, usaha Pasta Kangen Jupiter Daan Mogot Jakarta Barat dinyatakan layak untuk dijalankan.

c. Dengan pendekatan pesimis, usaha Pasta Kangen Jupiter Daan Mogot Jakarta Barat dinyatakan tidak layak untuk dijalankan, karena dari 6 (enam) metode Capital Budgeting hanya Payback Period (PP) yang dinyatakan layak, sedangkan Net Present Value (NPV) dinyatakan tidak layak, Profitability Index (PI) dinyatakan tidak layak, Average Rate of Return (ARR) dinyatakan tidak layak, Internal rate of Return (IRR) dinyatakan tidak layak, dan Discounted Payback Period (DPP) dinyatakan tidak layak.

\section{Referensi}

Aprilianto, G.S., Defidelwina, \& Gunawan, I. (2016). Financial Feasibility of Kerupuk Jari Processing Business In Pasir Utama Village Rambah Hilir District Rokan Hulu Regency.

Fahmi, Irham. (2015). Manajemen Investasi. Edisi ke-2. Jakarta: Salemba Empat.

Farida, Fitri Nur. (2004). Analisis Kelayakan Pengembangan Usaha Perternakan Ayam Ras Pedaging Melalui Program Kemitraan Terpadu, Jurusan Teknik Industri, STT-Garut, Garut.

Hery. (2015). Analisis Kinerja Manajemen. Jakarta: PT Grasindo.

Kasmir, \& Jakfar. (2012). Studi Kelayakan Bisnis. Edisi Revisi. Jakarta: Kencana Prenada Media Grup. Maulana, Y., Mauludin, Y., \& Gunadhi, E. (2014). Analisis Usaha Pertenakan Ayam Ras Pedaging (Broiler) Dengan Pola Kemitraan. Studi Kasus Di Pertenakan Bu Lilis Rancamidin, Cibodas. Jurnal STT-Garut.

Prawironegoro, D., \& Ari, P. (2008). Penganggaran Perusahaan. Edisi Pertama. Jakarta: Mitra Wacana Media.

Putri, N.D., El Hadi, R., \& Dellarosawati, M. (2017). Analisis Kelayakan Pengembangan Toko Pakaian HI.NC yang ditinjau pada Aspek Pasar, Aspek Teknis, dan Aspek Financial, e-Proceeding. Vol. 4. No. 2, 2705-2709.

Radoni, A., \& Herni, A. (2014). Manajemen Keuangan Modern. Jakarta: Mitra Wacana Gramedia.

Sinaga, Dadjim. (2009). Studi Kelayakaan Bisnis Dalam Ekonomi Global. Edisi Pertama. Jakarta: Mitra Wacana Media.

Sjahrial, Dermawan. (2007). Manajemen Keuangan. Edisi Pertama. Jakarta: Mitra Wacana Media. Sunyoto, Danang. (2014). Studi Kelayakan Bisnis. Jakarta: Caps Publishing.

Umar, Husein. (2003). Business: An Introduction. Edisi Kedua. Jakarta: Gramedia Pustaka Utama. 